fishes have been thawed into life after having been frozen for any great length of time.

* Dr. Richardson's remarks in a recent communication to Nature, upon "Suspended Animation," are pertinent to this inquiry. "It is hard to say whether an animal, like a fish, frozen equally through all its structure, is actually dead in the strict sense of the word, seeing that if it be equally and uniformly thawed it may recover from a perfect glacial state. In like manner it may be doubted whether a healthy, warmblooded animal suddenly and equally frozen through all its'parts is dead, although it is not recoverable, because in the very act of trying to restore it some inequality in the direction is almost certain to determine a fatal issue, owing to the transition of some vital centre into the pectous state of colloidal matter. I do not, consequently, see that cold can be of itself and alone utilized for maintaining suspended animation in the larger warm-blooded animals of full growth. * * * It is worthy of note that cold is antiseptic, as though whatever suspended living action, suspended also by some necessity or correlative influence the process of putrefactive decay."

Respectfully submitted.

Hon. Spencer F. Batkd,

J. H. KIDDER.

United States Commissioner of Fish

and Fisheries, Washington, D. C.

February 10, 1880.

\title{
DESCRIPTIONS OF NEW GENERA AND SPECIES OF FISHES FROA THE COAST OF CALIFORNIA.
}

\section{By W. N. LOCKING'TON.}

1. Leurynnis paucidens, gen. et sp. nov.

Generic characters.-Family Zoarcida, allied to Lycodes. Ventral fins present, short; no teeth on vomer and palatines; dorsal and anal fins continued without interruption around the tail. Scales small, but evident. The name is from levpos-smooth; ives_-vomer, in allusion to the character which chiefly distingnishes the genus from Lycodes.

SPECIFIC CHARACTERS.-Body elongate, eel-like; extremity of snont subtruncate; profile of remainder of snout and head conic, slightly convex over the eyes; highest part of the dorsal outline and deepest part of the fish perpendicular to a point about midway between the posterior end of the lower jaw and the base of the pectoral ; from this point to the slightly rounded end of the caudal the body tapers regularly both above and below. Head broad, the sides (viewed from above) almost straight from the opercula to about half-way between the eye and the tip of the snout, thence rapidly approaching and meeting in an obtuse point.

Greatest depth of body from a little more than ten to a little less than eleven times; length of head $4 \frac{1}{3}-4 \frac{2}{3}$ times in the total length; snout $2 \frac{13}{16}$ 
-3 times; eye $5 \frac{2}{5}-6 \frac{1}{4}$ times in the length of the head; lower jaw $\frac{11}{18}-\frac{13}{2}$ of the head. Pectoral fin $\frac{9}{22}-\frac{1}{2}$ the length of the head, and $4 \frac{1}{2}$ to almost 6 times the length of the ventrals; anus situated at the end of the second fifth of the total length.

Nostrils much nearer to the extremity of the snout than to the eye and below the horizon of the lower margin of the orbit; provided with a short tube.

Eyes elliptical, directed obliquely upwards and outwards; the interocular space only about $\frac{1}{6}$ of the total width of the head, the sides of which continue to shelve outwards at the same angle with the eye-balls as far as the lower margin of the suborbital ring. Interorbital space concave to about the center of the orbit, at which point the two ridges bordering the eyes unite with the central ridge, separating again posteriorly.

Mouth large, slightly oblique, the cleft straight, its angle reaching about to a vertical from the center of the pupil; intermaxillaries and maxillaries very slender; lower jaw received within the upper; lower margin of mandible straight, with a small symphysial knob, and a prominent articulation. In the females the mouth is smaller; maxillary with its posterior extremity enveloped in the skin of the angle of the mouth. Tongue large and thick.

Teeth small, slender, bluntly pointed, those of the mandible in about four irregular rows in front, those of the inner row largest and farthest apart. The outer row disappears at about $\frac{1}{4}$ of the length of the cleft of the mouth from the tip of the mandible, but the inner row continues to about $\frac{1}{2}$ the length of the cleft of the mouth. The outer row slopes out. ward, but the inner is much recurved, and the three or four posterior teeth of the inner row on each side are the largest and strongest in the jaws. Teeth of the intermaxillary in a single row, extending about half-way along the sides of the mouth, the largest in front, gradually diminishing posteriorly. No vomerine or palatine teeth.

Gill-openings narrow, inclined forwards, and broadly attached to the isthmus; branchiostegals six, sometimes only five. Pseudobranchiæ. Operculum very small, with radiating ridges; cheeks fleshy, very long, so that the eye is nearly midway between front of opercle and tip of snout. Upper and lower pharyngeal bones covered with villiform teeth; the posterior upper pharyngeal smallest; the lower pharyngeals separate, subtriangular. Gill-rakers quite short, pointed, flexible.

Vertical fins continuous, long and low, and formed of soft rays throughout, dorsal commencing at a vertical from a little before the center of the length of the pectoral, caudal somewhat rounded, anal commencing very near to the anus. Dorsal with about 90 rays; anal with about 70.

Ventrals very small, jugular, consisting of two rays; their insertion slightly posterior to the lower extremity of the branchial opening.

Upper axil of pectorals below the center of the height of the body, 
their base vertical, and extending to the abdominal outline; the fin consisting of 18 rays, the fifth or sixth longest, the lowest about $\frac{2}{3}$ as long as the fifth; first three or four rays simple, the others bifureate.

No lateral line. Scales roundish, smooth, separate, embedded in the skin, uniform over the whole of the body, except upon an area on the upper surface in front of the dorsal, where they are smaller, and region near base of pectorals scaleless. Head scaleless, the ridges somewhat prominent.

Color olivaceous, the scales lighter than the skin; the color formed by numerous dark points, which are continued also upon the head. Upper suirface of head darker, abdominal surface lighter than other portions. Vertical fins margined with black.

This species is not uncommon in the markets at San Francisco. Two specimens, 10 to 12 inches in length, have been forwarded to the United States National Museum, where they are numbered 23502. They may be considered as the types of the species.

\section{Odontopyxis trispinosus, gen. and sp. nov.}

Generic characters.-Family Agonide, allied to Agonus (cataphractus), from which it differs chiefly in the presence of teeth on the vomer and palatines. It is distinguished from Agonopsis, Gill, by its smaller fins and slenderer form.

Specific characters.-Body octahedral, the lower flat side terminating behind the anal fin, the upper side a little behind the second dorsal. Posterior portion of body hexagonal. Body anteriorly very much broader than deep, the upper side, from the head to its termination, concave; lower side slightly concave; the other surfaces flat. Lateral surfaces (traversed by the lateral line) wider anteriorly than those separating them from the upper and lower surfaces; posterior to the second dorsal the lateral surfaces are narrowest.

Greatest depth, above pectoral, 10-12 times in length; greatest width, at gill-covers, $7 \frac{5}{9}-8$; length of head, $5 \frac{2}{5}-5 \frac{4}{5}$ times in the total length; eye, $3 \frac{1}{2}-3 \frac{4}{5}$; snout, $3 \frac{1}{2}-3 \frac{4}{5}$; interorbital width, $6 \frac{1}{3}-7$ times in length of head.

Head triangular, depressed. A sharp, rather long, movable spine upon the tip of the snout, its triangular base projecting beyond the jaws; behind this central spine, on the highest point of the snout, is a pair of similar, but recurved, fixed spines. Snout posterior to these spines nearly level to orbital region. A prominent supra-orbital ridge ending posteriorly in a backward-directed spine. Forehead strongly convex longitudinally, and strongly concave transversely. Occiput slightly depressed between the par-occipital ridges, its posterior border deeply emarginated. Supra-occipital ridge but slightly marked above, but very conspicuous on the hinder margin of the head, where there is a deep cavity in front of the first series of body-plates, this eavity longitudinally divided by the supra-oceipital ridge. A slightly-marked ridge from the center of the hinder margin of the eye to the lateral keel of 
the upper surface. A backward-directed spine on each pre-orbital. Nostrils in a depression on each side of the snout. Lower jaw received within the upper both on front and sides. Jaws, vomer, and palatines armed with minute, sharp, closely set teeth.

Maxillary almost entirely concealed by the free edge of the pre-orbital when the mouth is closed. Two minute barbels at each angle of mouth. Orbit large, almost circular, occupying far the larger portion of the height of the head, the upper margin of the pupil touching a line drawn from the upper part of the snout to the occiput.

Gill-membranes attached to a broad isthmus; branchiostegals seven.

Pectoral shorter than head, broadly rounded on lower margin, and composed of fourteen simple rays.

Ventrals inserted posterior to the insertion of the pectorals, close together, consisting of a spine and two unbranched rays.

Vent a conspicuous elliptical opening, situated at about the middle of the length of the ventrals.

First dorsal of four spines, the second longest, the fourth shortest, the third slightly longer than the first; its base occupying the posterior portion of the seventh, and the whole of the eighth and ninth series of plates.

Second dorsal of six unbranched rays, the second slightly longer than the first; its base occupying the fifteenth to the nineteenth series of plates, inclusive.

Anal of six rays, opposite and similar to the soft dorsal.

Caudal elongate, rounded on posterior margin, and consisting of eleren unbranched rays. Fin-membranes delicate.

Thirty-five to thirty-seven series of plates from occiput to base of caudal, each series strongly keeled, each keel ending in a spine; a circlet of horizontal spines around the base of the caudal. The two elongate, subrectangular shields at the base of the ventrals are in the line of the second series of dorsal plates, the first series terminating above the pectorals. Twenty-seven irregular plates on the under surface of the body in front of the ventral plates. Lateral line simple, along the center of the lateral surfaces.

Color olivaceous or yellowish, with six or seven darker bands of brown on the dorsal surfaces. Under side uniform whitish. Fins blotched with blackish.

Three specimens of this species are known to me; two of them were obtained in the markets of San Francisco. One of these, which may be considered as the type of the species, has been forwarded to the United States National Museum, and is numbered 23504 on the Museum Register. The third specimen was procured on the coast of Alaska by the United States Coast Survey. The aspect of this fish is that of Agonus, but the presence of teeth on the vomer and palatines excludes it from that genus. 
Dimensions.

Total length

No. 2.

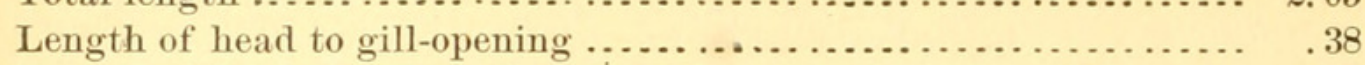

Length of head to center of occipital emargination ............. . 33

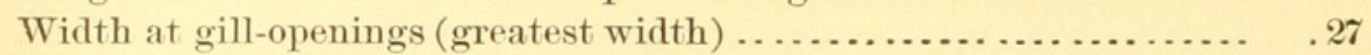

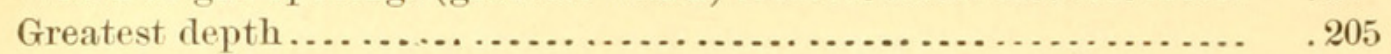

Tip of snout to pectoral base ................................ 40

Tip of snout to ventral base ................................. 46

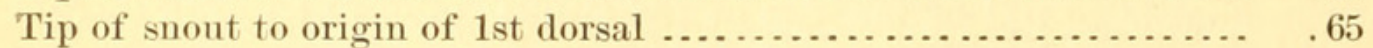

Tip of snout to origin of $2 d$ dorsal............................. $\quad .94$

3.23

Tip of snout to origin of anal ................................

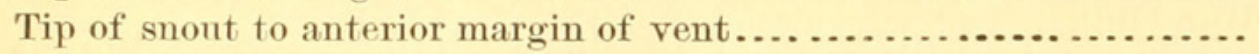

Length of snout ...........................................

Longitudinal diameter of orbit ..............................

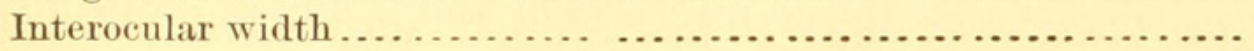

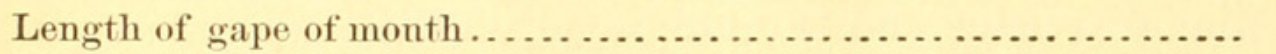

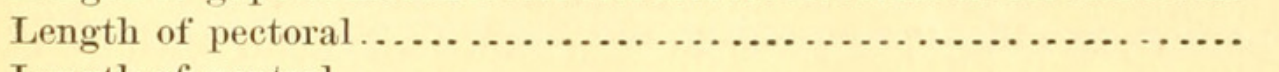

Length of ventral.................................... 13

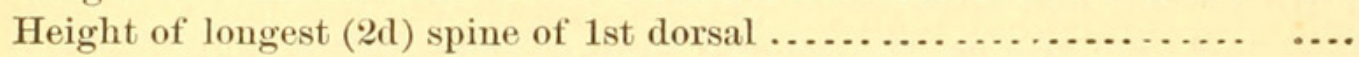

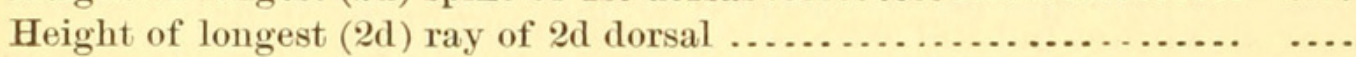

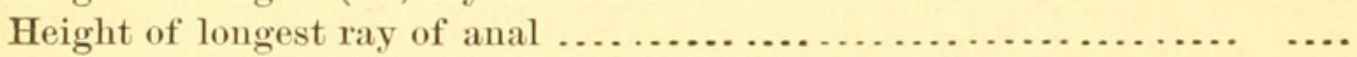

Number of series of plates (on back) and of tubes of lateral line ... 35

Fin-formula: B. 7; P. 14 ; VI, 2; D. IV-6; A. 6; C. 11.

The dimensions are all taken along the axis of the fish.

3. Artedius quadriseriatus, sp. nov.
B. 5 ; D. $\frac{\mathrm{IX}-\mathrm{X}}{14}$;
A. $12 ;$ P. 16
V. $4 ;$ C.
C. $2,11,2$; Lat. line $35-37$.

Snout straight, rising at an angle of about $45^{\circ}$, forehead strongly curved, occipital region slightly concave, depth of body at origin of dorsal only slightly exceeding that at posterior margin of orbit. A conspicuous supra-orbital barbel about half as long as diameter of eye. Dorsal outline from origin of dorsal to caudal peduncle straight and deflected regularly downwards.

Gape of mouth very slightly oblique, rest of abdominal profile straight. Greatest width (at preopercles) $6 \frac{4}{11}$ to nearly 7 , greatest depth (at origin of dorsal) about equal to greatest width; length of head (to tip of operculum) $2 \frac{5}{9}$ times, in total length to end of caudal. Snout about equal to longitudinal diameter of orbit which is about $3 \frac{2}{3}$ times in head; interocular width 121 $-14 \frac{1}{2}$ times in length of head. Depth of eaudal peduncle $3 \frac{1}{2}$ times in greatest length, pectoral about $1 \frac{1}{5}$ in length of head.

Head large, deep ; ascending processes of premaxillaries forming two converging ridges, ending above in a blunt projection, on each side of which, in a line with the nostrils, is a long sharp spine. A pair of spines on occiput, the interval between them concave transversely. A transverse sulcus between the anterior pair of spines and the forehead.

Eyes directed obliquely upwards, interocular space concave, narrow, less than $\frac{1}{3}$ the width of the eye.

Gape of mouth slightly oblique, maxillary reaching to the middle of the pupil, its end with a slender barbel; mandible straight; jaws even when the mouth is closed. 
A band of closely set, sharp, nearly straight, eardiform teeth in both jaws, the largest teeth in the front of the jaws, where there are more rows than at the sides. Similar teeth on vomer and palatines. Cushions of villiform teeth on pharyngeals.

Gill-rakers tubercular; branchiostegals five, gill-membranes broadly connected below the throat; no isthmus. Pseudobranchiæ present.

Preoperculum with a large process which has four curved spines above and ends in a spine directed backwards. Sometimes there is a fifth spine on the upper margin, or the tip is bifid. Three other preopercular spines, the uppermost a little below the spine-bearing process, and directed backwards, the next pointing downwards, the lowest obliquely forwards, the three last equidistant. Supra-scapula with a ridge, in a line with the first scale of the lateral line. Upper surface and sides of the head with numerous pores, the most conspicuous of which are on the anterior portion of the forehead. Top and sides of head with some minute, smooth, imbedded scales. Opercle small, ending posteriorly in a flat, bluntish spine, behind which is a large membranous flap.

First five spines of first dorsal sub-equal, the others diminishing rapidly, last very short. Two dorsals entirely separate, interval short.

Second dorsal increasing in height to fourth or fifth ray, first ray about $\frac{3}{4}$ as long as second. From the longest ray the upper margin inclines regularly to the last (14th), which is about $\frac{1}{2}$ the length of the longest.

Anal similar to soft dorsal, but the rays shorter, fourth ray longest. Origin of 1st dorsal opposite the center of the supra-scapular ridge, that of $2 \mathrm{~d}$ opposite the 11th scale of the lateral line, anal arising opposite the $2 d$, and terminating opposite the 13th ray of the $2 d$ dorsal.

Pectoral base oblique, broad, pectoral broadly lanceolate, 5th ray longest and extending back to the 2 nd ray of the $2 d$ dorsal.

Ventrals small, four-rayed, inserted slightly behind the posterior axil of the pectoral base; length to that of pectoral as 2.8 . All fin-rays anbranched.

Each side of the body with two bands of large, strongly ctenoid scales; the lower bearing the lateral line, composed of 35 to 37 scales, beginning at the upper angle of the gill-openings, thence strongly decurved over the pectorals, thence running straight to the base of the caudal. Many of the scales on the posterior part of this band are provided with slender cirri. The upper band of scales begins further back, in front of the middle of the dorsal, and runs along the base of the dorsal fins, stopping before reaching the caudal. This band is composed of two series of alternating scales, closely wedged in together. Between and above these bands are a few small scattered imbedded scales. Like the scales on the head these small scales can only be seen with the aid of a magnifying-glass.

Color olivaceous, with darker spots formed of black punctulations; four or five dark blotches along the lateral line. Branchiostegal mem- 
brane sometimes black. Two black spots on the spinous dorsal, one in front, the other at the tips of the posterior rays. Other fins olivaceous.

Pectorals and caudal barred; ventrals and anal sometimes black, sometimes colorless. Under surface creamy-white.

Several specimens obtained in San Francisco market among heaps of Pandalus Dance. Two of these now in the United States Museum are numbered 23503 on the register.

As the specimens obtained vary less than is the case with many species, and are of very nearly the same dimensions, I subjoin measurements of two only.

The principal variations are in the height of the dorsals and in the color of the paired fins and of the anal, which are much darker in some than in others. The dimensions are all axial, unless otherwise stated.

Total length, to tip of caudal

Inches. Inches.

Total length, without caudal

$3.38 \quad 3.50$

Length of head, to tip of operculum . . . . . . . . . . . . . . . . . . . $\quad .95 \quad .99$

Greatest depth of body at origin of 1 st dorsal $\ldots \ldots \ldots \ldots \ldots \ldots \ldots \ldots . \quad .47 \quad .55$

Greatest width at preopercles . . . . . . . . . . . . . . . . . . . . . . 49.55

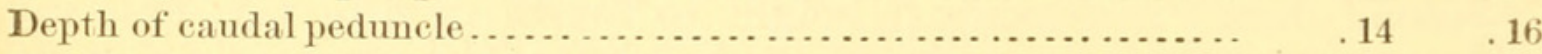

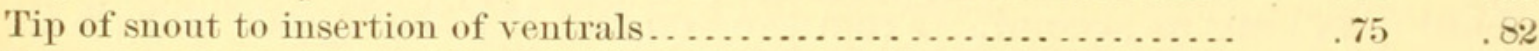

Tip of snout to origin of 1 st dorsal . . . . . . . . . . . . . . . . . . . . . . $80 \quad .80 \quad .83$

Tip of snout to origin of 1 st dorsal along dorsal outline $\ldots \ldots \ldots \ldots \ldots . \quad .90 \quad .95$

Tip of snout to origin of 2 nd dorsal . . . . . . . . . . . . . . . . . . . . . . 1.44 1.54

Tip of snout to origin of anal ............................. 1.46 1.56

Height of longest ray of 1 st dorsal . . . . . . . . . . . . . . . . . . . . . . . $46 \quad .41$

Height of longest ray of 2 nd dorsal $\ldots \ldots \ldots \ldots \ldots \ldots \ldots \ldots \ldots \ldots \ldots \ldots \ldots . \quad .45 \quad \ldots .$.

Length of base of 1 st dorsal . . . . . . . . . . . . . . . . . . . . . . . . . . . . $56 \quad .58$

Length of base of 2 nd dorsal . . . . . . . . . . . . . . . . . . . . . . . . . . 85

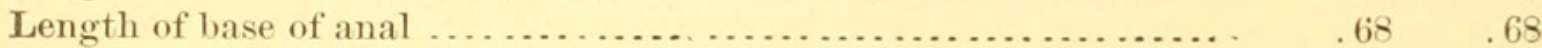

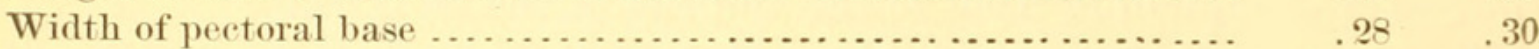

Length of pectoral, from center of base $\ldots \ldots \ldots \ldots \ldots \ldots \ldots \ldots \ldots \ldots \ldots . . . \ldots \ldots$

Length of ventrals .................................... . . $31 \quad .31$

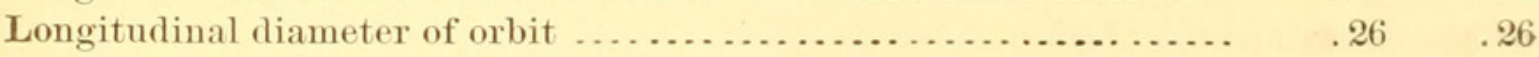

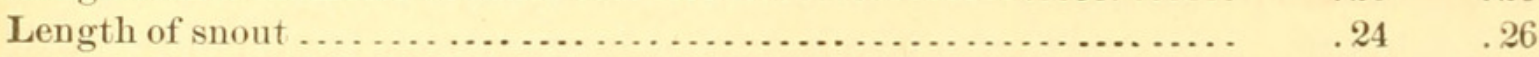

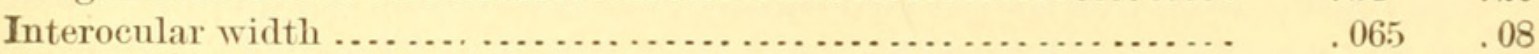

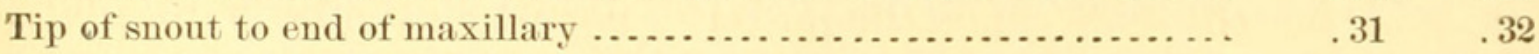

Length of preopercular process ........................ .21 .22

San Francisco, December, 1879. 


\section{$2 \mathrm{BHL}$ Biodiversity Heritage Library}

Lockington, W N. 1880. "Descriptions of new genera and species of fishes from the coast of California." Proceedings of the United States National Museum 2(97), 326-332. https://doi.org/10.5479/si.00963801.97.326.

View This Item Online: https://www.biodiversitylibrary.org/item/31794

DOI: https://doi.org/10.5479/si.00963801.97.326

Permalink: https://www.biodiversitylibrary.org/partpdf/29651

\section{Holding Institution}

Smithsonian Libraries

\section{Sponsored by}

Smithsonian

\section{Copyright \& Reuse}

Copyright Status: NOT_IN_COPYRIGHT

This document was created from content at the Biodiversity Heritage Library, the world's largest open access digital library for biodiversity literature and archives. Visit BHL at https://www.biodiversitylibrary.org. 